\title{
Preoperative factors predicting the severity of BMD loss around the implant after Total hip Arthroplasty
}

\author{
Akira Morita ${ }^{1}$, Naomi Kobayashi² ${ }^{*}$, Hyonmin Choe ${ }^{1}$, Taro Tezuka' ${ }^{1}$ Shota Higashihira ${ }^{1}$ and Yutaka Inaba ${ }^{1}$
}

\begin{abstract}
Background: Stress shielding after total hip arthroplasty (THA) leads to loss of bone mineral density (BMD) around the femoral implants, particularly in the proximal area. Loss of BMD around the implant is likely to occur within 1 year after THA; however, its severity depends on patient characteristics. This study evaluated preoperative factors correlated with the severity of zone 7 BMD loss after THA.
\end{abstract}

Methods: This retrospective cohort study included 48 patients who underwent primary THA from October 2011 to December 2015. All patients underwent implantation of a Zweymüller-type femoral component without any postoperative osteoporosis medications. The objective variable was a change in zone 7 BMD after 1 year. Factors evaluated included age, body mass index, Japanese Orthopaedic Association score, Harris Hip Score, Canal Flare Index (CFI), and lumbar BMD on the frontal and lateral sides. Univariate and multivariate regression analyses identified factors correlated with loss of zone 7 BMD.

Results: Univariate regression analysis identified CFI $(P=0.003)$ and preoperative lumbar BMD on the anteriorposterior $(P=0.003)$ and lateral $(P<0.001)$ sides as being correlated with loss of zone $7 \mathrm{BMD}$. Multivariate regression analysis identified CFI $(P=0.014)$ and lumbar BMD on the lateral side $(P<0.001)$ as being correlated independently with loss of zone $7 \mathrm{BMD}$.

Conclusion: Lower preoperative lumbar BMD on the lateral side and lower CFI were correlated with zone 7 BMD loss after THA. Patients with these characteristics should be monitored carefully for severe BMD loss after THA.

Keywords: Total hip arthroplasty, Bone mineral density, Canal flare index, Zweymüller

\section{Introduction}

Total hip arthroplasty (THA) is an established surgical method for patients with hip joint diseases such as osteoarthritis and osteonecrosis of the femoral head; THA results in stable long-term clinical outcomes, including pain relief and improvements in performance of activities of daily living (ADL) $[1,2]$. However, THA can lead to a reduction in bone mineral density (BMD)

\footnotetext{
* Correspondence: naomik58@aol.com

${ }^{2}$ Department of Orthopaedic Surgery, Yokohama City University Medical Center, 4-57 Urafune-cho, Minami-ku, Yokohama 232-0024, Japan Full list of author information is available at the end of the article
}

around the implant, particularly in proximal parts such as Gruen's zones 1 and 7 [3-5]. Although loss of BMD around the implant does not worsen clinical outcomes directly, it is associated with increased risk of periprosthetic fracture and late loosening $[6,7]$. Thus, maintaining $\mathrm{BMD}$ around the implant provides stable long-term clinical outcomes.

The main cause of BMD loss around the implant is stress shielding, which is caused by changes in mechanical stress properties after implantation [4]. Several studies have assessed the ability of several drugs, including bisphosphonate and teriparatide, to prevent loss of BMD

(c) The Author(s). 2021 Open Access This article is licensed under a Creative Commons Attribution 4.0 International License, which permits use, sharing, adaptation, distribution and reproduction in any medium or format, as long as you give appropriate credit to the original author(s) and the source, provide a link to the Creative Commons licence, and indicate if changes were made. The images or other third party material in this article are included in the article's Creative Commons licence, unless indicated otherwise in a credit line to the material. If material is not included in the article's Creative Commons licence and your intended use is not permitted by statutory regulation or exceeds the permitted use, you will need to obtain permission directly from the copyright holder. To view a copy of this licence, visit http://creativecommons.org/licenses/by/4.0/ The Creative Commons Public Domain Dedication waiver (http://creativecommons.org/publicdomain/zero/1.0/) applies to the data made available in this article, unless otherwise stated in a credit line to the data. 
around implants following THA [8-12]. Because loss of BMD may also be associated with preoperative patientspecific factors, these findings suggest that drug interventions should be initiated immediately after THA, particularly in selected patients at higher risk of BMD loss. Therefore, this study sought to identify preoperative factors that predict the severity of BMD loss around implants after THA.

\section{Patients and methods}

This retrospective cohort study evaluated patients diagnosed with osteoarthritis of the hip or osteonecrosis of the femoral head who underwent primary THA at Yokohama City University hospital from October 2011 to December 2015 (Fig. 1). Patients were excluded if they received non-target implants, were treated with drugs for osteoporosis or corticosteroids, or were diagnosed with a condition other than osteoarthritis of the hip or osteonecrosis of the femoral head. Patients were also excluded if not all data, including BMD and X-rays, were available 1 year after surgery. Preoperative patient activity levels were evaluated by measuring the activity score, the Japanese Orthopaedic Association (JOA) hip score, and the Harris Hip Score (HHS).

All patients were operated on using a direct lateral approach and all received the same cementless femoral component of a Zweymüller-type stem (SL-PLUS MIA, Smith and Nephew, Inc. Memphis, TN), a cementless acetabular component (REFLECTION, Smith and Nephew, Inc.), and a cross-linked polyethylene liner
(XLPE liner, Smith and Nephew, Inc.). All patients began using a wheelchair on the first postoperative day, all started gait exercises with full weight bearing as soon as possible thereafter. Dual-energy X-ray absorptiometry (DEXA) (QDR 2000, Hologic, Waltham, MA) was used to measure baseline periprosthetic BMD 1 week after THA, followed by subsequent measurements at 1-year intervals. Regions of interest (ROIs) were centered on the periprosthetic zones described by Gruen (Fig. 2). At 1 week pre-surgery, DEXA was used to measure the BMD of the lumbar (L) vertebrae (L2 to L4) in the anterior-posterior (AP) and lateral directions.

The primary outcome variable was a change in zone 7 BMD 1 year after THA; the secondary outcome variable was a change in BMD in zones 1-6. Explanatory variables included age, body mass index (BMI), the preoperative Japanese Orthopaedic Association (JOA) score, the Harris Hip Score (HHS), the Canal Flare Index (CFI) (Fig. 3), and lumbar BMD on the AP and lateral sides.

\section{Statistical analysis}

To analyze the factors that periprosthetic loss of BMD after THA, a regression analysis was performed. At first, a univariate regression analysis was performed with the following factors as explanatory variables: age, BMI, JOA score, HHS, CFI, lumbar BMD on the AP side and lateral side. Furthermore, variables with $p$-values $<0.05$ were populated for regression analysis as a multivariate assessment and entered into the final equation. Standardized regression coefficients $(\beta)$ and associated $p$ -

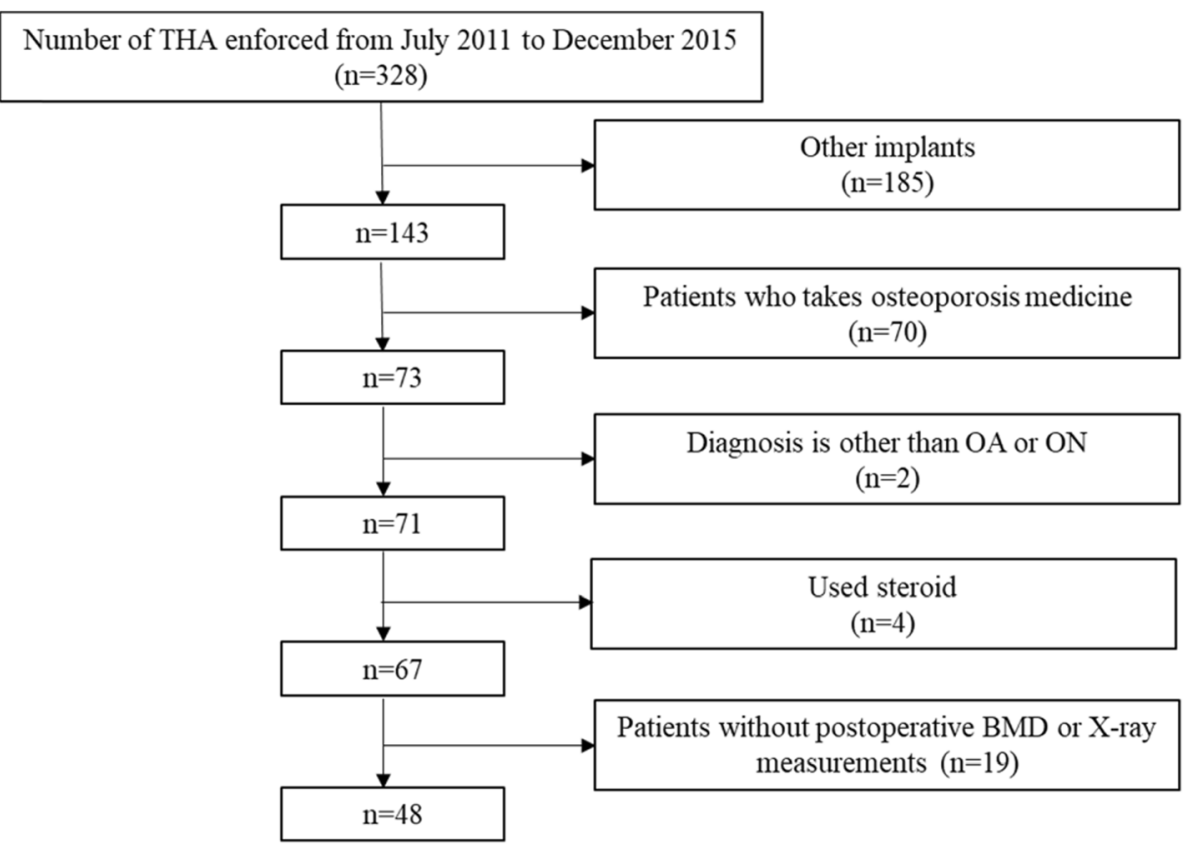

Fig. 1 Flow chart showing the patient selection process 


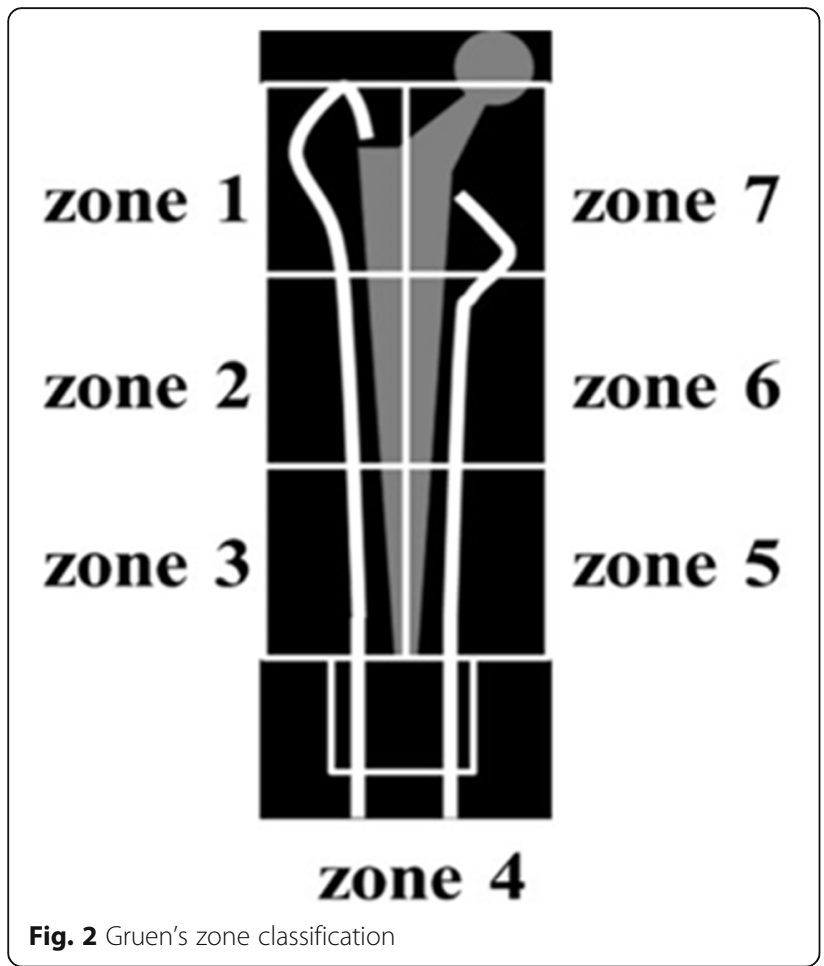

values were determined to assess statistical significance $(p<0.05)$. Univariate regression analysis and multivariate regression analysis analyses were performed using SPSS II software (SPSS Japan, Inc., Tokyo, Japan).

\section{Results}

Of the 328 patients who underwent primary THA from October 2011 to December 2015, 280 were excluded (185 who received non-target implants, 70 who were taking medications for osteoporosis, two who were diagnosed with a condition other than osteoarthritis of the hip or osteonecrosis of the femoral head, four who were taking steroids, and 19 for whom data were missing (e.g., results of BMD measurements and X-rays)).

The mean ( \pm standard deviation) age of the 48 enrolled patients was $64.0 \pm 12.0$ years and the mean BMI at the time of surgery was $24.0 \pm 4.2 \mathrm{~kg} / \mathrm{m}^{2}$. Table 1 shows the demographic and clinical characteristics of the cohort, and Fig. 4 shows the periprosthetic changes in BMD for each zone at 1 year postsurgery. Relative to baseline, the mean percentage changes in BMD for zones 1-7 at 1 year were $10.9 \pm 9.7,-9.3 \% \pm 11.5,-3.7 \% \pm 8.6 \%,+0.9 \% \pm 5.5 \%$, $+0.8 \% \pm 6.1 \%, \quad-12.9 \% \pm 12.8 \%$, and $-32.8 \% \pm 15.3 \%$, respectively. Table 2 shows the results of univariate regression analysis of the association between changes in BMD at zones 1-7 and exploratory variables. Scatter plots showed that the percentage change in zone 7 BMD from baseline to 1 year post-surgery

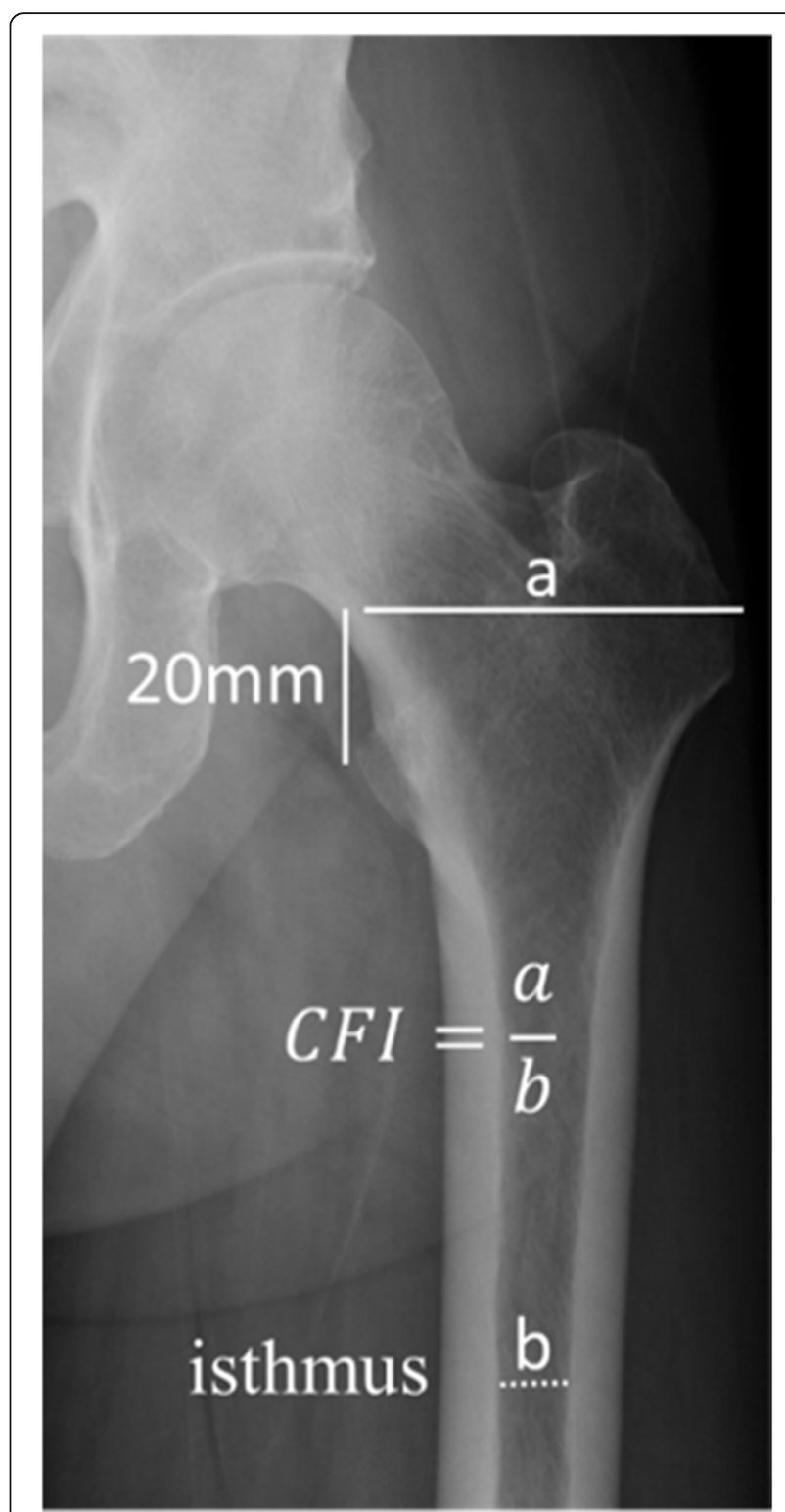

Fig. 3 Canal flare index

Table 1 Demographic and clinical characteristics of the 48 patients included in the study

\begin{tabular}{ll}
\hline Variable & Mean \pm SD \\
\hline Age $(\mathrm{yr})$ & $64.0 \pm 12.0$ \\
Male/Female & $9 / 39$ \\
Body Mass Index $\left(\mathrm{kg} / \mathrm{m}^{2}\right)$ & $24.0 \pm 4.2$ \\
Japanese Orthopaedic Association score & $52.0 \pm 14.0$ \\
Harris Hip Score & $51.8 \pm 15.4$ \\
Canal Flare Index & $4.2 \pm 0.8$ \\
Lumbar BMD on the AP side $\left(\mathrm{g} / \mathrm{cm}^{2}\right)$ & $1.0 \pm 0.2$ \\
Lumbar BMD on the lateral side $\left(\mathrm{g} / \mathrm{cm}^{2}\right)$ & $0.7 \pm 0.1$ \\
\hline
\end{tabular}




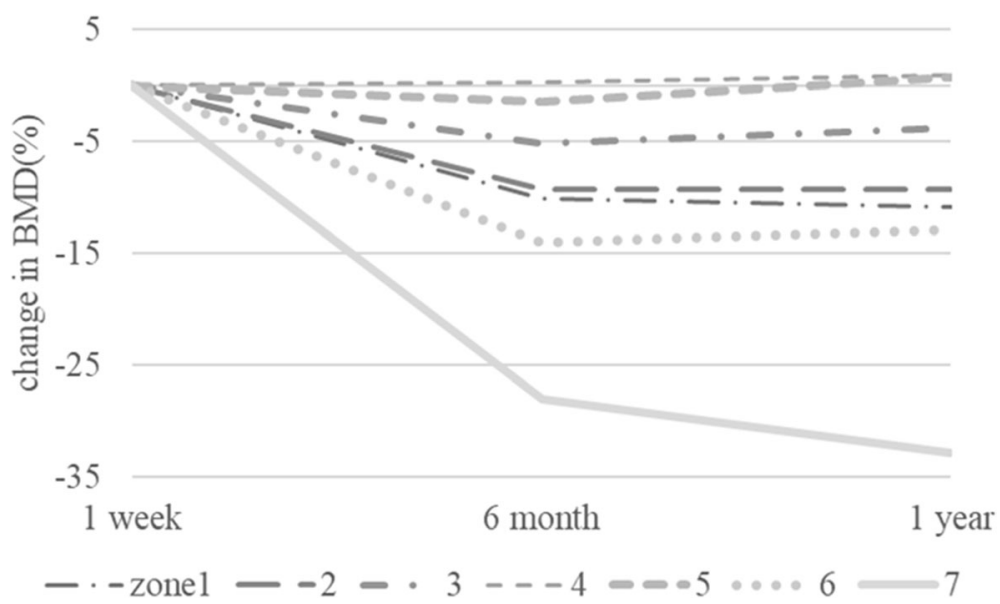

Fig. 4 Time course of percent change in BMD from baseline in each Gruen zone over 1 year

correlated with preoperative CFI $\left(\mathrm{R}^{2}=0.177, \quad P=\right.$ 0.003) (Fig. 5), preoperative lumbar $\mathrm{BMD}$ on the AP side $\left(\mathrm{R}^{2}=0.194, P=0.003\right)$ (Fig. 6), and preoperative lumbar $\mathrm{BMD}$ on the lateral side $\left(\mathrm{R}^{2}=0.310, P<\right.$ 0.001) (Fig. 7). Multivariate regression analysis showed that the percentage change from baseline in zone 2 correlated with lumbar BMD on the AP side $(\beta=$ $0.344, P=0.024$ ) (adjusted $\mathrm{R}^{2}=0.119$ ). In zone 5 , it correlated with age $(\beta=0.344, P=0.012)$ and BMI $(\beta=-0.293, P=0.032)$ (adjusted $\left.R^{2}=0.196\right)$; in zone 6 it correlated with lumbar BMD on the lateral side ( $\beta=0.357, P=0.019$ ) (adjusted $R^{2}=0.106$ ); and in zone 7 it correlated with CFI $(\beta=0.322, P=0.014)$ and lumbar BMD on the lateral side $(\beta=0.48, P<$ 0.001) (adjusted $\mathrm{R}^{2}=0.408$ ) (Table 3 ).

\section{Discussion}

This retrospective cohort study investigated preoperative factors correlated with periprosthetic BMD loss after THA. Multivariate regression analysis showed that preoperative CFI and lumbar BMD on the lateral side correlated with BMD loss in zone 7. These findings emphasize the importance of monitoring patients for severe BMD loss after THA, particularly patients with lower $\mathrm{BMD}$ in the lumbar region and a stovepipeshaped proximal femur.

BMD loss around the implant is common after THA $[13,14]$. The most important cause is stress shielding, which is influenced mainly by stem design. A comparison of patients undergoing THA with the Zweymüller stem or fit-and-fill stem implants found that mechanical

Table 2 Univariate regression of associations between changes in BMD in each zone and exploratory variables*

\begin{tabular}{|c|c|c|c|c|c|c|c|}
\hline Variables & Zone 1 & Zone 2 & Zone 3 & Zone 4 & Zone 5 & Zone 6 & Zone 7 \\
\hline \multirow[t]{2}{*}{ Age (yr) } & $r=0.174$ & $r=0.270$ & $r=0.143$ & $r=0.073$ & $r=0.382$ & $r=0.128$ & $r=0.172$ \\
\hline & $P=0.238$ & $P=0.063$ & $P=0.333$ & $P=0.622$ & $P=0.007$ & $P=0.387$ & $P=0.242$ \\
\hline \multirow[t]{2}{*}{ Body Mass Index $\left(\mathrm{kg} / \mathrm{m}^{2}\right)$} & $r=-0.102$ & $r=0.021$ & $r=0.045$ & $r=0.043$ & $r=-0.337$ & $r=0.034$ & $r=-0.063$ \\
\hline & $P=0.491$ & $P=0.886$ & $P=0.760$ & $P=0.770$ & $P=0.019$ & $P=0.818$ & $P=0.672$ \\
\hline \multirow[t]{2}{*}{ Japanese Orthopaedic Association score } & $r=0.153$ & $r=0.240$ & $r=0.090$ & $r=-0.064$ & $r=0.104$ & $r=-0.050$ & $r=0.223$ \\
\hline & $P=0.306$ & $P=0.104$ & $P=0.548$ & $P=0.667$ & $P=0.487$ & $P=0.736$ & $P=0.132$ \\
\hline \multirow[t]{2}{*}{ Harris Hip Score } & $r=0.041$ & $r=0.108$ & $r=-0.019$ & $r=0.014$ & $r=0.051$ & $r=-0.139$ & $r=0.134$ \\
\hline & $P=0.782$ & $P=0.471$ & $P=0.901$ & $P=0.924$ & $P=0.736$ & $P=0.351$ & $P=0.369$ \\
\hline \multirow[t]{2}{*}{ Canal Flare Index } & $r=0.108$ & $r=0.294$ & $r=0.243$ & $r=0.026$ & $r=0.045$ & $r=0.189$ & $r=0.421$ \\
\hline & $P=0.467$ & $P=0.043$ & $P=0.096$ & $P=0.859$ & $P=0.761$ & $P=0.198$ & $P=0.003$ \\
\hline \multirow[t]{2}{*}{ Lumbar BMD on the AP side $\left(\mathrm{g} / \mathrm{cm}^{2}\right)$} & $r=0.006$ & $r=0.344$ & $r=0.157$ & $r=-0.135$ & $r=-0.190$ & $r=0.178$ & $r=0.440$ \\
\hline & $P=0.968$ & $P=0.024$ & $P=0.314$ & $P=0.389$ & $P=0.223$ & $P=0.252$ & $P=0.003$ \\
\hline \multirow[t]{2}{*}{ Lumbar BMD on the lateral side $\left(\mathrm{g} / \mathrm{cm}^{2}\right.$} & $r=0.066$ & $r=0.335$ & $r=0.165$ & $r=0.109$ & $r=0.080$ & $r=0.357$ & $r=0.557$ \\
\hline & $P=0.672$ & $P=0.028$ & $P=0.291$ & $\boldsymbol{P}=0.487$ & $P=0.609$ & $P=0.019$ & $P<0.001$ \\
\hline
\end{tabular}

*Significant values are shown in bold 


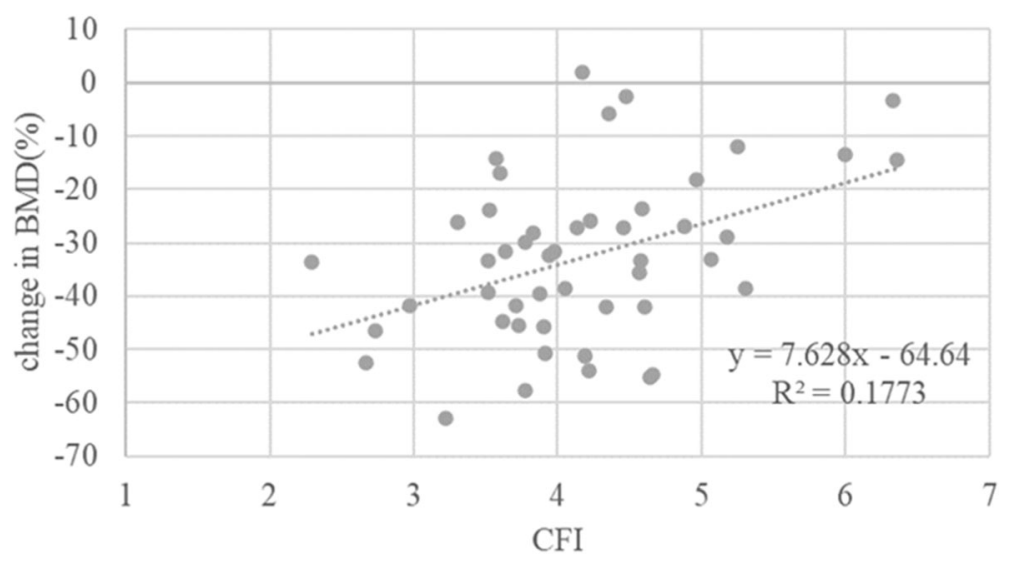

Fig. 5 Scatter plot showing the relationship between the percentage change in zone 7 BMD and CFI from baseline to 1 year post-surgery $\left(R^{2}=\right.$ $0.177, r=0.421, P=0.003$ )

stress and zone 7 BMD loss around the implant were lower in those receiving the Zweymüller stem [4].

Loss of BMD may also be associated with patientspecific or operative factors. For example, excessive stem anteversion mismatched with anatomical canal anteversion results in contact between the stem point and the cortical bone in the distal portion, thereby affecting proximal periprosthetic zone 7 BMD loss after THA [15, 16]. An investigation of postoperative zone $7 \mathrm{BMD}$ in groups of patients with normal preoperative lumbar BMD and patients with osteopenia and osteoporosis found that BMD loss was significantly higher in the osteopenia and osteoporosis groups than in the normal group [17], indicating that periprosthetic BMD loss is associated with bone quality as well as stress shielding [18]. In this study, we confirmed that CFI correlates with zone 7 BMD loss. Although it was less relevant in univariate regression analysis, the adjusted $\mathrm{R}^{2}$ obtained from multivariate regression analysis was 0.408 when including both CFI and lumbar BMD on the lateral side. Thus, the equation might be helpful for predicting loss of BMD in zone 7.

Because loss of BMD in the proximal femur, particularly zone 7 , is likely to be lower than that in other zones and occurs within 1 year postoperatively [17], it is important to take steps to prevent it. Many drugs are used to prevent loss of BMD around the implant after THA; one example is bisphosphonate [10, 11, 19-24]. Moreover, bisphosphonate are associated with a lower risk of aseptic revision in patients undergoing primary THA for osteoarthritis [21]. However, long-term continuous treatment with bisphosphonate is associated with atypical periprosthetic fractures $[23,24]$. A study of a large US cohort reported that the periprosthetic fracture rate following primary THA was $1.1 \%$ [23]. Data from the Swedish hip registry suggest a rate of $0.64 \%$ over 10 years [24]; the latter also showed that bisphosphonate are associated with a higher risk of periprosthetic

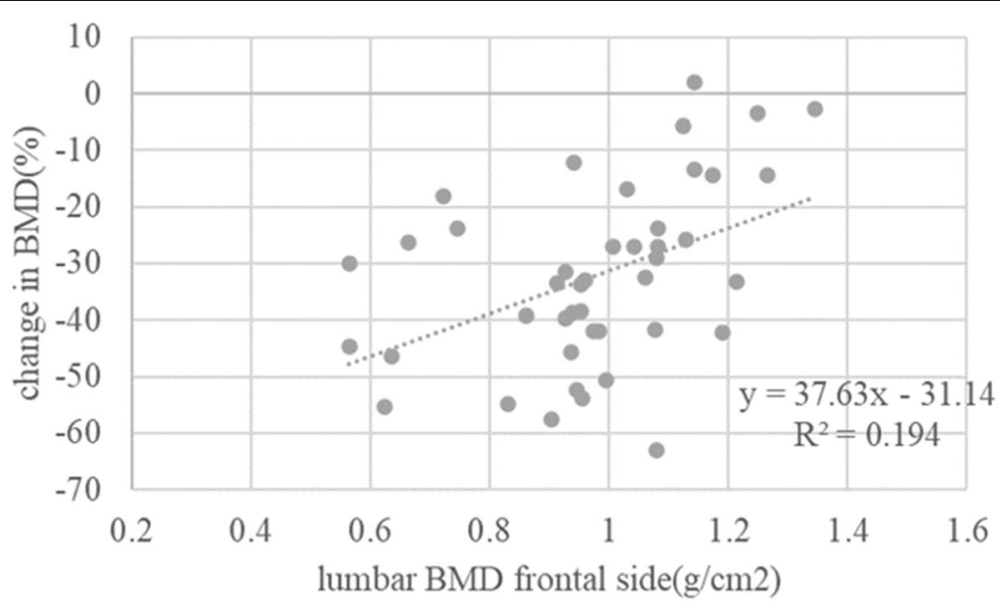

Fig. 6 Scatter plot showing the relationship between the percentage change in zone 7 BMD and preoperative lumbar BMD on the frontal side from baseline to 1 year post-surgery $\left(R^{2}=0.194, r=0.440, P=0.003\right)$ 


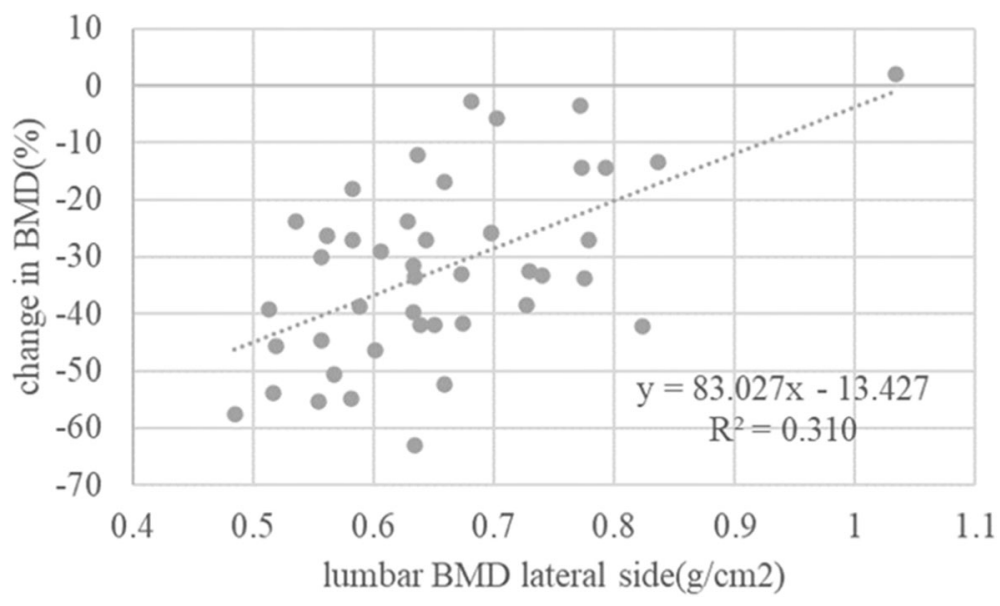

Fig. 7 Scatter plot showing the relationship between the percentage change in zone 7 BMD and preoperative BMD on the lateral side from baseline to 1 year post-surgery $\left(R^{2}=0.310, r=0.557, P<0.001\right)$

fracture in younger patients with normal bone quantity [24]. Another effective agent that can prevent loss of $\mathrm{BMD}$ around the implant is teriparatide. A randomized controlled trial found that teriparatide and alendronate were equally effective for preventing zone 7 BMD loss [11]. Moreover, switching from teriparatide to alendronate is effective [12]. Although several drugs prevent loss of BMD around the implant after THA, care is necessary regarding the side effects and economic burden of these agents.

The shape of the femoral medullary cavity is related to loss of BMD around the implant. A previous study shows that postoperative zone $7 \mathrm{BMD}$ is significantly lower in stovepipe-shaped than in champagne-fluteshaped cavities when using taper-wedge-type stems [25]. The stovepipe-shaped type of medullary cavity has a small CFI, making these results similar to those of the present study. By contrast, a comparison of postoperative changes in BMD in any zone with respect to three types of medullary cavity (stovepipe, normal, and champagne-flute shaped) after implantation of a Zweymüller-type stem found no statistically significant difference in relative changes between the groups [26]. Here, we found that patients with low CFI, such as those with a stovepipe-shaped medullary cavity, showed a greater reduction in postoperative zone $7 \mathrm{BMD}$ than patients with high CFI, such as those with a champagne-fluteshaped cavity.

Regarding other zones (1-6), univariate regression analysis showed that CFI and lumbar BMD correlated with BMD changes in zone 2. This result is similar to that observed for zone 7; thus, BMD loss in the proximal area may be correlated with CFI and lumbar BMD. By contrast, we found a correlation between age and changes in BMD in zone 5. When using the Zweymüller stem, a wide femoral canal and thin cortical bone correlate positively with increased bone density below the stem, resulting in hypertrophy of the cortical bone in the

Table 3 Multivariate regression of associations between changes in BMD in each zone and exploratory variables

\begin{tabular}{|c|c|c|c|c|c|}
\hline & Variables & $\begin{array}{l}\text { Regression } \\
\text { coefficient }\end{array}$ & $\beta$ & P-value & Adjusted $\mathrm{R}^{2}$ \\
\hline \multirow[t]{2}{*}{ Zone 2} & & & & & 0.119 \\
\hline & Lumbar BMD on the AP side $\left(\mathrm{g} / \mathrm{cm}^{2}\right)$ & 21.958 & 0.344 & 0.024 & \\
\hline \multirow[t]{3}{*}{ Zone 5} & & & & & 0.196 \\
\hline & Age (yr) & 0.180 & 0.344 & 0.012 & \\
\hline & Body Mass Index $\left(\mathrm{kg} / \mathrm{m}^{2}\right)$ & -0.428 & -0.293 & 0.032 & \\
\hline \multirow[t]{2}{*}{ Zone 6} & & & & & 0.106 \\
\hline & Lumbar BMD on the lateral side $\left(\mathrm{g} / \mathrm{cm}^{2}\right)$ & 44.011 & 0.357 & 0.019 & \\
\hline \multirow[t]{3}{*}{ Zone 7} & & & & & 0.408 \\
\hline & $\mathrm{CFI}$ & 5.741 & 0.322 & 0.014 & \\
\hline & Lumbar BMD on the lateral side $\left(\mathrm{g} / \mathrm{cm}^{2}\right)$ & 71.653 & 0.480 & $<0.001$ & \\
\hline
\end{tabular}


distal femur [27]. The canal flare index and cortical index for both sexes decreases with age [28], which may explain the correlation between age and changes in BMD in zone 5. In addition, we also found a weak correlation between BMD changes in zone 5 and BMI. Hayashi et al. [29] found no correlation between BMI and periprosthetic BMD when using a cementless triple tapered stem. This difference may be due to the implants used. Nevertheless, these zonal losses of BMD (except those in zone 7) are mild and may not be clinically important.

Finally, there is no clear evidence that BMD loss in zone 7 is directly related to lower survival rates of implants used for THA. However, in terms of preventing periprosthetic fractures, maintaining BMD around the implant is desirable. Therefore, in addition to implant design, it may be desirable to administer osteoporosispreventing drugs after surgery, particularly in cases with lower lumbar BMD and lower CFI.

\section{Study limitations}

This study has several limitations. First, we investigated only patients with Zweymüller-type stems. Studies of other stem types, such as taper-wedge stems, may yield different results. Second, the total number of evaluated subjects was small, as many subjects had to be excluded.

\section{Conclusion}

Lower preoperative lumbar BMD on the lateral side and lower CFI correlated with zone 7 BMD loss at 1 year post-THA. Patients at risk of BMD loss may benefit from pre- or postoperative drug treatment to prevent this.

\section{Abbreviations}

THA: Total hip arthroplasty; BMD: Bone mineral density; BMI: Body mass index; JOA: Japanese Orthopaedic Association; HHS: Harris Hip Score; CFI: Canal Flare Index; ADL: Activities of daily living; DEXA: Dual-energy X-ray absorptiometry; ROls: Regions of interest; AP: Anterior-posterior

\section{Acknowledgements}

The authors express their sincere appreciation to all those who supported the research and helped to prepare the manuscript.

\section{Authors' contributions}

NK contributed to study design, and manuscript preparation and revision. AM collected and analyzed patient data and prepared the draft manuscript. $\mathrm{HC}$ and SH analyzed the patient data. $\Pi \mathrm{T}$ and $\mathrm{Yl}$ interpreted the results. All authors read and approved the final version of the manuscript.

\section{Funding}

This research did not receive any specific grant from funding agencies in the public, commercial, or not-for-profit sectors.

\section{Availability of data and materials}

The datasets used and/or analyzed during the current study are available from the corresponding author upon reasonable request.

\section{Declarations}

All clinical studies were conducted in accordance with ICMJE guidelines.
Ethics approval and consent to participate

Ethical approval was provided by the Yokohama City University ethical committee (number B191200033). Informed consent was obtained in the form of opt-out on the web-site.

\section{Consent for publication}

Not applicable.

\section{Competing interests}

The authors declare no competing interests.

\section{Author details}

'Department of Orthopaedic Surgery, Yokohama City University, 3-9 Fukuura, Kanazawa-ku, Yokohama 236-0004, Japan. ${ }^{2}$ Department of Orthopaedic Surgery, Yokohama City University Medical Center, 4-57 Urafune-cho, Minami-ku, Yokohama 232-0024, Japan.

Received: 16 December 2020 Accepted: 9 March 2021

Published online: 19 March 2021

\section{References}

1. Al Muderis M, Bohling U, Grittner U, et al. Cementless total hip arthroplasty using the Spongiosa-l fully coated cancellous metal surface: a minimum twenty-year follow-up. J Bone Joint Surg Am. 2011;93(11):1039-44. https:// doi.org/10.2106/JBJS.I.01757.

2. McLaughlin JR, Lee KR. Uncemented total hip arthroplasty with a tapered femoral component: a 22- to 26-year follow-up study. Orthopedics. 2010;33: 639. https://doi.org/10.3928/01477447-20100722-40.

3. Kröger $H$, Venesmaa $P$, Jurvelin J, et al. Bone density at the proximal femur after total hip arthroplasty. Clin Orthop Relat Res. 1998:66-74. http://www. ncbi.nlm.nih.gov/pubmed/9678034

4. Hirata $Y$, Inaba $Y$, Kobayashi N, Ike H, Fujimaki H, Saito T. Comparison of mechanical stress and change in bone mineral density between two types of femoral implant using finite element analysis. J Arthroplasty. 2013;28(10): 1731-5. https://doi.org/10.1016/j.arth.2013.04.034.

5. Ike H, Inaba Y, Kobayashi N, Hirata Y, Yukizawa Y, Aoki C, et al. Comparison between mechanical stress and bone mineral density in the femur after total hip arthroplasty by using subject-specific finite element analyses. Comput Methods Biomech Biomed Engin. 2015;18(10):1056-65. https://doi. org/10.1080/10255842.2013.869320.

6. Leonardsson O, Kärrholm J, Åkesson K, Garellick G, Rogmark C. Higher risk of reoperation for bipolar and uncemented hemiarthroplasty. Acta Orthop. 2012;83(5):459-66. https://doi.org/10.3109/17453674.2012.727076.

7. Aro HT, Alm JJ, Moritz N, et al. Low BMD affects initial stability and delays stem osseointegration in cementless total hip arthroplasty in women: a 2year RSA study of 39 patients. In: Acta Orthopaedica; 2012.

8. Knusten AR, Ebramzadeh E, Longjohn DB, Sangiorgio SN. Systematic analysis of bisphosphonate intervention on periprosthetic BMD as a function of stem design. J Arthroplasty. 2014;29(6):1292-7. https://doi.org/10.1016/j.a rth.2014.01.015.

9. Iwamoto N, Inaba Y, Kobayashi N, Ishida T, Yukizawa Y, Saito T. A comparison of the effects of alendronate and Alfacalcidol on bone mineral density around the femoral implant and in the lumbar spine after total hip arthroplasty. J Bone Jt Surgery-Am Vol. 2011;93(13):1203-9. https://doi.org/1 0.2106/JBJS.I.01714.

10. Arabmotlagh M, Pilz M, Warzecha J, Rauschmann M. Changes of femoral periprosthetic bone mineral density 6 years after treatment with alendronate following total hip arthroplasty. J Orthop Res. 2009;27(2):183-8. https://doi.org/10.1002/jor.20748.

11. Kobayashi N, Inaba Y, Uchiyama M, Ike H, Kubota S, Saito T. Teriparatide versus alendronate for the preservation of bone mineral density after Total hip Arthroplasty - a randomized controlled trial. J Arthroplasty. 2016;31(1): 333-8. https://doi.org/10.1016/j.arth.2015.07.017.

12. Morita A, Kobayashi N, Choe H, Ike H, Tezuka T, Higashihira S, et al. Effect of switching administration of alendronate after teriparatide for the prevention of BMD loss around the implant after total hip arthroplasty, 2-year followup: a randomized controlled trial. J Orthop Surg Res. 2020;15(1):17. https:// doi.org/10.1186/s13018-020-1547-5.

13. Nishii T, Sugano N, Masuhara K, Shibuya T, Ochi T, Tamura S. Longitudinal evaluation of time related bone remodeling after cementless total hip 
arthroplasty. Clin Orthop Relat Res. 1997;339:121-31. https://doi.org/10.1097/ 00003086-199706000-00017.

14. Venesmaa PK, Kröger HPJ, Miettinen HJA, Jurvelin JS, Suomalainen OT, Alhava EM. Monitoring of Periprosthetic BMD after uncemented total hip Arthroplasty with dual-energy X-ray absorptiometry-a 3-year follow-up study. J Bone Miner Res. 2001;16(6):1056-61. https://doi.org/10.1359/jbmr.2 001.16.6.1056

15. Hayashi S, Hashimoto S, Matsumoto T, Takayama K, Nishida K, Ishida K, et al. Stem anteversion mismatch to the anatomical anteversion causes loss of periprosthetic bone density after THA. J Orthop Surg. 2017;25(3): 230949901773947. https://doi.org/10.1177/2309499017739478.

16. Hayashi S, Hashimoto S, Kanzaki N, Kuroda R, Kurosaka M. Stem Anteversion affects Periprosthetic bone mineral density after Total HIP Arthroplasty. Hip Int. 2016;26(3):260-4. https://doi.org/10.5301/hipint.5000363.

17. Alm JJ, Mäkinen TJ, Lankinen P, Moritz N, Vahlberg T, Aro HT. Female patients with low systemic BMD are prone to bone loss in Gruen zone 7 after cementless total hip arthroplasty. Acta Orthop. 2009;80(5):531-7. https://doi.org/10.3109/17453670903316801.

18. Venesmaa PK, Kröger HPJ, Miettinen HJA, Jurvelin JS, Suomalainen OT, Alhava EM. Monitoring of Periprosthetic BMD after Uncemented Total hip Arthroplasty with dual-energy X-ray absorptiometry-a 3-year follow-up study. J Bone Miner Res. 2001;16(6):1056-61. https://doi.org/10.1359/jbmr.2 001.16.6.1056.

19. Kinov P, Tivchev P, Doukova P, Leithner A. Effect of risedronate on bone metabolism after total hip arthroplasty: a prospective randomised study. Acta Orthop Belg. 2006;72:44-50

20. Yamaguchi K, Masuhara K, Yamasaki S, Nakai T, Fuji T. Cyclic therapy with etidronate has a therapeutic effect against local osteoporosis after cementless total hip arthroplasty. Bone. 2003;33(1):144-9. https://doi.org/1 0.1016/S8756-3282(03)00085-1.

21. Yamasaki S, Masuhara K, Yamaguchi K, Nakai T, Fuji T, Seino Y. Risedronate reduces postoperative bone resorption after cementless total hip arthroplasty. Osteoporos Int. 2007;18(7):1009-15. https://doi.org/10.1007/ s00198-007-0339-7.

22. Teng S, Yi C, Krettek C, Jagodzinski M. Bisphosphonate use and risk of implant revision after Total hip/knee Arthroplasty: a meta-analysis of observational studies. PLoS One. 2015;10(10):e0139927. https://doi.org/10.13 71/journal.pone.0139927.

23. Erviti J, Alonso Á, Oliva B, Gorricho J, López A, Timoner J, et al. Oral bisphosphonates are associated with increased risk of subtrochanteric and diaphyseal fractures in elderly women: a nested case-control study. BM Open. 2013;3(1):e002091. https://doi.org/10.1136/bmjopen-2012-002091.

24. Goh S-K, Yang KY, Koh JSB, Wong MK, Chua SY, Chua DTC, et al. Subtrochanteric insufficiency fractures in patients on alendronate therapy. J Bone Joint Surg Br. 2007;89-B(3):349-53. https://doi.org/10.1302/0301-620X. 89B3.18146.

25. Oba M, Inaba Y, Kobayashi N, Ike H, Tezuka T, Saito T. Effect of femoral canal shape on mechanical stress distribution and adaptive bone remodelling around a cementless tapered-wedge stem. Bone Joint Res. 2016;5(9):362-9. https://doi.org/10.1302/2046-3758.59.2000525.

26. Nakamura S, Minoda Y, Ohta Y, Sugama R, Yamamura K, Ueyama H, et al. Preoperative morphology of the proximal Femoral Canal did not affect the postoperative bone mineral density change around the Zweymüller-type stem. Orthopedics. 2019;42(5):e449-53. https://doi.org/10.3928/01477447-2 0190604-04

27. Kokoszka P, Markuszewski J, Łapaj Ł, Wierusz-Kozłowska M. Remodeling of bone tissue around the distal part of Zweymüller stem. Ortop Traumatol Rehabil. 2015;17(4):371-80. https://doi.org/10.5604/15093492.1173379.

28. Casper DS, Kim GK, Parvizi J, Freeman TA. Morphology of the proximal femur differs widely with age and sex: relevance to design and selection of femoral prostheses. J Orthop Res. 2012;30(7):1162-6. https://doi.org/10.1002/ jor.22052.

29. Hayashi S, Nishiyama T, Fujishiro T, Kanzaki N, Hashimoto S, Kurosaka M. Periprosthetic bone mineral density with a cementless triple tapered stem is dependent on daily activity. Int Orthop. 2012;36(6):1137-42. https://doi. org/10.1007/s00264-011-1407-3

\section{Publisher's Note}

Springer Nature remains neutral with regard to jurisdictional claims in published maps and institutional affiliations.

\section{Ready to submit your research? Choose BMC and benefit from:}

- fast, convenient online submission

- thorough peer review by experienced researchers in your field

- rapid publication on acceptance

- support for research data, including large and complex data types

- gold Open Access which fosters wider collaboration and increased citations

- maximum visibility for your research: over $100 \mathrm{M}$ website views per year

At $\mathrm{BMC}$, research is always in progress.

Learn more biomedcentral.com/submissions 